\title{
Dissolved iron transport pathways in the Ross Sea: Influence of tides and horizontal resolution in a regional ocean model
}

\author{
Stefanie L. Mack ${ }^{\mathrm{a}, 1, *}$, Michael S. Dinniman ${ }^{\mathrm{a}}$, Dennis J. McGillicuddy, Jr. ${ }^{\mathrm{b}}$, \\ Peter N. Sedwick ${ }^{\mathrm{c}}$, John M. Klinck ${ }^{\mathrm{a}}$ \\ ${ }^{a}$ Center for Coastal Physical Oceanography, Old Dominion University, Norfolk, VA USA \\ 23529 \\ ${ }^{b}$ Woods Hole Oceanographic Institution, Woods Hole, MA 02543 \\ ${ }^{c}$ Department of Ocean, Earth, and Atmospheric Sciences, Old Dominion University, \\ Norfolk, VA, USA 23529
}

\section{Abstract}

Phytoplankton production in the Ross Sea is regulated by the availability of dissolved iron (dFe), a limiting micro-nutrient, whose sources include Circumpolar Deep Water, sea ice melt, glacial melt, and benthic sources (sediment efflux and remineralization). We employ a passive tracer dye to model the benthic dFe sources and track pathways from deep areas of the continental shelf to the surface mixed layer in simulations with and without tidal forcing, and at 5 and $1.5 \mathrm{~km}$ horizontal resolution. This, combined with dyes for each of the other dFe sources, provides an estimate of total dFe supply to surface waters. We find that tidal forcing increases the amount of benthic dye that covers the banks on the continental shelf. Calculations of mixed layer depth to define the surface ocean give similar average values over the

\footnotetext{
*Corresponding Author

Email address: macksl@uw.edu (Stefanie L. Mack)

${ }^{1}$ Present address: Applied Physics Laboratory, University of Washington, Seattle, WA 98105
} 
shelf, but spatial patterns differ between simulations, particularly along the ice shelf front. Benthic dFe supply in simulations shows an increase with tidal forcing and a decrease with higher resolution. The changes in benthic dFe supply control the difference in total supply between simulations. Overall, the total dFe supply from simulations varies from 5.60 to $7.95 \mu \mathrm{mol} \mathrm{m}^{-2} \mathrm{yr}^{-1}$, with benthic supply comprising 32-50\%, comparing well with recent data and model synthesis. We suggest that including tides and using high horizontal resolution is important, especially when considering spatial variability of iron supply on the Ross Sea shelf.

Keywords: Ross Sea, Tides, Mesoscale, Modelling, Tracers

\section{Introduction}

2 The Ross Sea, Antarctica is home to a unique ecosystem (Smith et al., 3 2007). Each spring, a significant phytoplankton bloom starts in the Ross

4 Sea polynya, and spreads to other areas as the sea ice melts, making the ${ }_{5}$ Ross Sea among the most productive region in the Southern Ocean (Ar6 rigo et al., 2008). The phytoplankton are dominated by diatom species and 7 Phaeocystis Antarctica, which provide food for larger plankton, including a 8 keystone species of the region, Antarctic krill (Euphausia superba) (Smith 9 et al., 2007). These lower trophic levels support a variety of top predators, including penguins, seals, fish, birds, and whales.

Annual primary production by phytoplankton is limited by the availability of dissolved iron (dFe), an essential micro-nutrient (Tagliabue and Arrigo, 2005; Sedwick et al., 2011). Deep mixing over the winter months sets up a 
there is sufficient solar radiation, and then drawn down to growth limiting concentrations $(0.1 \mathrm{nM})$ during spring and summer. Four major sources of dFe to surface waters in the Ross Sea are: glacial melt water, sea ice melt water (including atmospheric deposition on sea ice), Circumpolar Deep Water (CDW), and benthic sources (which can include a direct efflux from sediments and remineralization) (McGillicuddy et al., 2015). The transport of $\mathrm{dFe}$ to the surface waters and the subsequent characteristics of the spring bloom are likely influenced by local, mesoscale processes, such as icebergs, sea ice melt, and eddies (Boyd et al., 2012). Thus, the entire ecosystem in this area is heavily influenced by the physical processes that bring dFe to surface waters.

Tides and mesoscale eddies have small temporal and small spatial scales, respectively, that should influence the amount of dFe supplied to the surface mixed layer (SML). In the Ross Sea, tidal flows reach up to $1 \mathrm{~ms}^{-1}$ near the continental shelf break (Padman et al., 2009), enhancing cross slope water exchange and increasing the amount of CDW advected onto the shelf (Wang et al., 2013). Tidal rectification has been shown to increase basal melting rates of the Ross Ice Shelf (MacAyeal, 1985; Arzeno et al., 2014), potentially increasing glacial contributions of dFe supply. Similar mechanisms have been demonstrated for nearby shelf seas, where tides cause intensification of under ice shelf circulation (Makinson et al., 2011; Mueller et al., 2012; Robertson, 2013).

Mesoscale eddies in the open ocean can produce localized hot spots of primary production, as eddy pumping brings nutrients, including $\mathrm{dFe}$, from deeper waters to the surface (Falkowski et al., 1991; McGillicuddy Jr., 2016). 
In the case of Antarctic shelf ecosystems like the Weddell or Ross seas, eddies also may travel beneath the ice shelf, transporting water and flushing the ice shelf cavity (Årthun et al., 2013), increasing the amount of ice shelf melt water that reaches the continental shelf. Recent work shows eddies possibly provide a mechanism to enable meltwater from ice shelves to spread out into the open ocean away from a buoyancy driven ice shelf front coastal current (Li et al., 2016)(this issue). Through this combination of effects, eddies potentially affect the supply of glacial melt water to the continental shelf and the upwelling of dFe from CDW or benthic sources.

Following the work of McGillicuddy et al. (2015), this study focuses on simulating the benthic supply of dFe to the SML, and compares the strength of this source with other inputs from glacial melt water, sea ice melt water, and CDW. Specifically, we examine the contributions of tides and the effect of horizontal resolution in a regional ocean model, supplemented by data from a recent research cruise. Section 2 describes the data obtained from the cruise, and details the simulations and analysis methods. Results are presented in section 3 that detail the effects of tides and increased horizontal resolution on the transport pathways of benthic waters, the depth of the SML during austral summer, and the relative contribution to dFe from each identified source. A discussion of the results and their implications on the importance of including tides and high horizontal resolution in future simulations is presented in section 4 . 


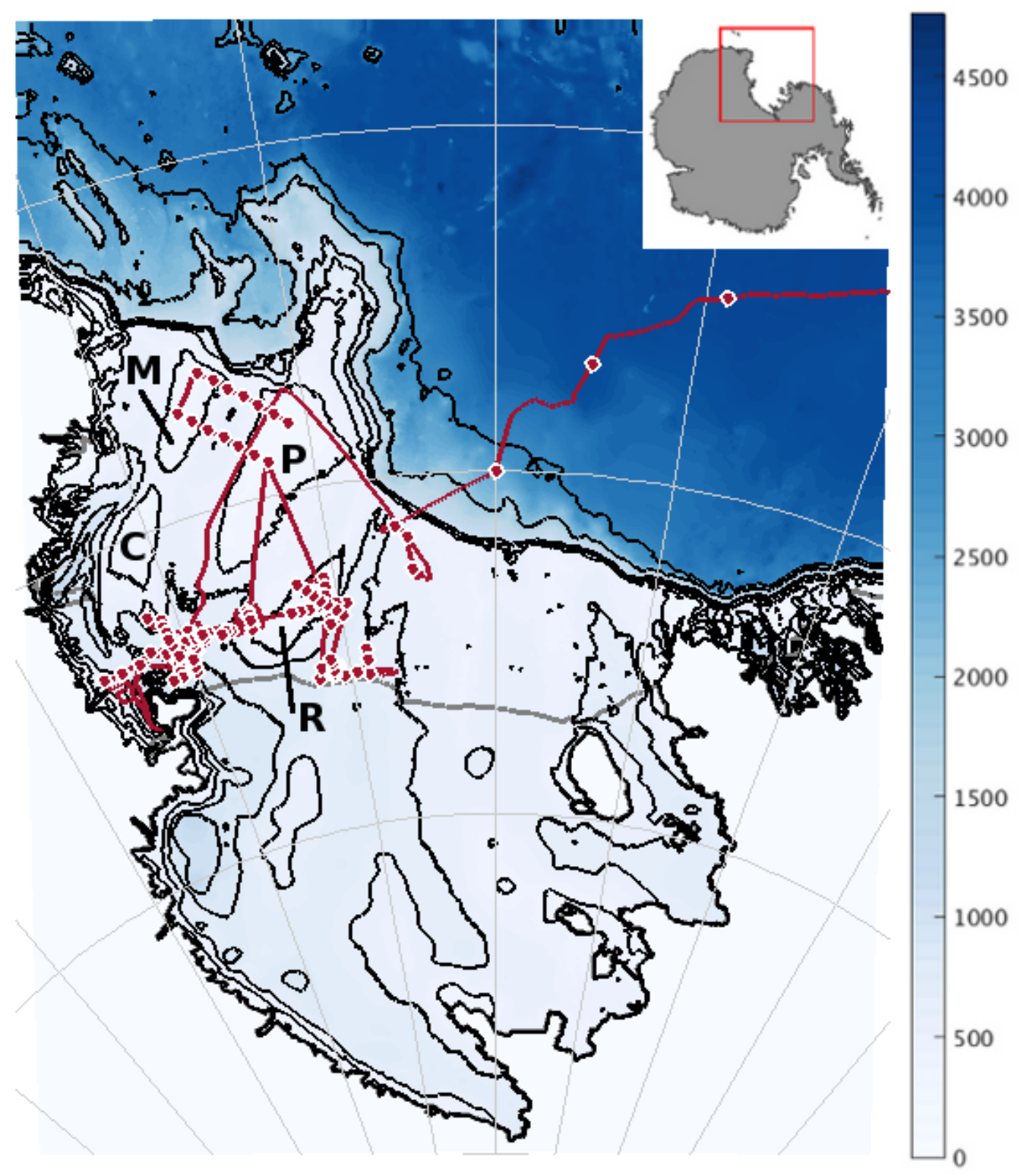

Figure 1: Model domain of the Ross Sea. Bottom depth is in meters. Red line is the PRISM-RS cruise track, dots are CTD stations. Black lines are bathymetry contours, gray is ice shelf edge. M: Mawson Bank; P: Pennell Bank; C: Crary Bank; R: Ross Bank. 


\begin{tabular}{c|c|c|c} 
Instrument & Resolution & Data Collected & Depth Range \\
\hline Underway & $500 \mathrm{~m}$ & T,S,F,V,W & Surface only \\
CTD & $10-20 \mathrm{~km}$ & T,S,F,I & All \\
MVP & $2-5 \mathrm{~km}$ & T,S,F,LOPC & $10-300 \mathrm{~m}$ \\
VPR & $1 \mathrm{~km}$ & T,S,F, images & $10-150 \mathrm{~m}$
\end{tabular}

Table 1: Relevant PRISM-RS cruise meta-data and approximate horizontal resolution. See Fig. 1. $\mathrm{T}=$ Temperature; $\mathrm{S}=$ Salinity; $\mathrm{F}=$ Fluorescence; $\mathrm{V}=$ Velocity; $\mathrm{W}=$ Wind; $\mathrm{I}=$ Dissolved iron LOPC $=$ Laser Optical Plankton Counter

\section{Methods}

\subsection{PRISM-RS Cruise}

The project Processes Regulating Iron Supply at the Mesoscale - Ross Sea (PRISM-RS) (McGillicuddy et al., 2015) undertook an oceanographic cruise aboard RVIB Nathaniel B. Palmer from December 24, 2011 to February 8, 2012 (Fig.1). The purpose of this project is to investigate the potential sources of iron during the spring bloom and to assess their roles in supporting the Ross Sea ecosystem. To this end, the cruise focused on hydrographic and trace metal measurements (Table 1), along with biological surveys of phytoplankton processes. Specifically, the data collected included temperature and salinity measurements from a variety of instruments including CTD casts, the ship's underway system, and a Moving Vessel Profiler (MVP). Iron measurements were made in samples collected using a trace metal CTD and towfish underway system. A towed Video Plankton Recorder (VPR) was used to collect information on phytoplankton distributions.

We use data from this cruise, specifically temperature and salinity mea- 
surements from CTD, MVP, and VPR, to compare with model estimates of mixed layer depth (MLD). As part of the MLD analysis, we also examine wind measurements from the underway data. Finally, to formulate the passive tracer dye described in section 2.3, we use dissolved iron measurements taken from the trace metal CTD samples (Marsay et al., 2014).

\subsection{Model Description}

The Ross Sea physical model is based on the Regional Ocean Modeling System (ROMS v3.6) framework with finite differencing schemes and vertical terrain-following levels (Haidvogel et al., 2008; Shchepetkin and McWilliams, 2005, 2009). This model was modified from a previous version (McGillicuddy et al., 2015; Dinniman et al., 2011, 2007), and includes the Ross Ice Shelf cavity, thermodynamic and mechanical effects of the ice shelf, and a coupled sea ice model (Budgell, 2005). Bathymetry and under ice shelf topography were updated using IBCSO (Arndt et al., 2013) and Bedmap2 (Fretwell et al., 2013), respectively. Both bathymetry products were smoothed, first with a Shapiro filter and then by hand, to eliminate pressure gradient force errors in regions with steep changes in bathymetry or topography with respect to the total depth. The vertical stretching scheme follows Song and Haidvogel (1994), with 24 vertical levels. Stretching parameters $\Theta_{s}$ and $\Theta_{b}$ are set to 4 and 0.9 , respectively, allowing for a concentration of layers at both the surface and bottom. For a standard on-shelf location that is 500 meters deep, the top layer is less than $5 \mathrm{~m}$ thick, the bottom layer is 12 meters thick, and layers at mid-depth are about $38 \mathrm{~m}$ thick.

Hindcast simulations were run for the period of September 15, 2010 through February 27, 2012. The simulation begins from a 6 year spin up 
following Dinniman et al. (2011). The spin up was forced by a two year repeating cycle of daily winds from AMPS, monthly AMPS climatologies of humidity, sea level pressure, air temperature, and precipitation, with cloud cover from ISCCP (International Satellite Cloud Climatology Product). The model is forced with 6 hourly winds and atmospheric temperatures, and with monthly climatologies of humidity, precipitation, and cloud cover, all from ERA-Interim (Dee et al., 2011). Monthly sea ice concentrations on the open boundaries are from SSM/I data, ocean temperatures and salinities are from climatology (World Ocean Atlas 2001), and barotropic velocities are from OCCAM (Ocean Circulation and Climate Advanced Model). Lateral open boundary conditions specify a radiation scheme on outflow, and a weak nudging on inflow. Vertical mixing of tracers and momentum is determined with the K-profile parameterization (KPP) scheme (Large et al., 1994), with the inclusion of a bottom boundary layer parameterization (Durski, 2004). Details of this mixing scheme can be found in Marsay et al. (2014), supplementary material.

The simulation time period allows the model to adjust from initial conditions. Calculations are performed over the last year of simulation, from the end of an austral summer season (i.e., March 1, 2011) through the next summer season. As the dye accumulates throughout the simulation, total dFe supply over the course of one year is estimated by calculating the net (instantaneous) amount of dFe in the SML at the end of the simulation. We note that by disregarding biological uptake processes, we underestimate the total supply of dFe in two ways: first, a less sharp vertical gradient of dFe decreases the amount brought to the surface by turbulent diffusion, and sec- 


\begin{tabular}{c|c|c} 
Simulation & Tidal Forcing & Horizontal Resolution \\
\hline $\mathbf{5}$ & No & $5 \mathrm{~km}$ \\
$\mathbf{5 T}$ & Yes & $5 \mathrm{~km}$ \\
$\mathbf{1}$ & No & $1.5 \mathrm{~km}$ \\
$\mathbf{1 T}$ & Yes & $1.5 \mathrm{~km}$ \\
S5 $^{*}$ & No & $5 \mathrm{~km}$
\end{tabular}

Table 2: Details of simulations used. ${ }^{*}$ Simulation $\mathbf{S 5}$ is a special case of $\mathbf{5}$ with repeat yearly forcing for 20 years.

ond, $\mathrm{dFe}$ that reaches the SML and leaves before the simulation end is not included.

In order to assess the effects of tides and horizontal grid resolution on $\mathrm{dFe}$ supply from various sources, we use four separate simulations (Table 2): with and without tidal forcing at two different horizontal resolutions. The tidally forced simulations include constituents $\mathrm{O} 1, \mathrm{~K} 1, \mathrm{M} 2$, and $\mathrm{S} 2$, which are added at the boundaries as both sea surface height and velocity, using the Flather boundary condition (Flather, 1976). Given the relatively small size of the regional model domain, including the tide-generating-force as a body force is not necessary. The amplitude and phase of the tidal constituents come from the CATS2008 tidal model Padman et al. (2003), and are nodally corrected. The model was run at two different resolutions, intended to be an eddypermitting resolution of $5 \mathrm{~km}$, and an eddy-resolving resolution of $1.5 \mathrm{~km}$. To properly resolve eddies, a ratio of two grid points per radius of deformation is needed (Hallberg, 2013). Based on an estimated $5 \mathrm{~km}$ radius of deformation for weakly stratified Antarctic continental shelves, a grid spac- 
ing of $1.5 \mathrm{~km}$ is sufficient to resolve mesoscale eddies (St-Laurent et al., 2013). However, mesoscale eddy dynamics on the Ross Sea continental shelf are not well understood. Specifically, the Ross Sea is very weakly stratified over the winter months, restricting the formation of mesoscale eddies. Any instabilities that appear would be more appropriately classified as submesoscale or three dimensional turbulence, and require a non-hydrostatic model to properly represent. A full analysis of mesoscale eddy dynamics in the Ross Sea is beyond the scope of the current study. Instead, we restrict our analysis to the effects of model horizontal resolution, keeping in mind that this includes sharper bathymetric features as well as potentially resolving mesoscale eddies. We note that a preliminary analysis shows an increase of about $20 \%$ in surface Eddy Kinetic Energy (EKE) on the continental shelf (inshore of $700 \mathrm{~m}$ ) in January/February 2012 with increased resolution.

A fifth simulation, S5, was designed to test model stability over time. Using the $5 \mathrm{~km}$ grid and no tidal forcing, we ran this simulation for 20 years, using repeat forcing from the year Sept 15, 2010 to Sept 15, 2011. The results from S5 allow us to make estimates of adjustment time to initial conditions and to determine that the model stabilizes over time and does not drift. These technical results are not presented in this paper, but the long time series provided by this simulation serve as a tool for determining significance between simulations, as set out in section 2.4.

\subsection{Passive Tracer Dyes}

The model includes four passive tracer dyes, three of which, representing CDW $\left(d y e_{C D W}\right)$, sea ice melt $\left(d y e_{S I M}\right)$, and glacial melt $\left(d y e_{G M}\right)$, have been detailed in previous studies (Dinniman et al., 2011; McGillicuddy et al., 
2015). In brief, $d y e_{C D W}$ is initialized in off shelf waters that meet the criterion for $\mathrm{CDW}$ (temperature greater than $0^{\circ} \mathrm{C}$ ), and is diffused and mixed onto the continental shelf by physical processes. Dye $e_{S I M}$ is input into the surface layer of the model as a function of positive sea ice melt (ice formation does not remove dye). Similarly, dye $e_{G M}$ is injected into the surface layer under the ice shelves as a function of positive glacial melt rate. Calculations of dye end member concentrations (Table 3) of dissolved iron and associated errors from observations are given in detail in McGillicuddy et al. (2015).

These three dyes are initialized at the beginning of the simulations and allowed to disperse throughout the model domain for the full year and a half. This allows $d y e_{C D W}$ and $d y e_{G M}$ to travel from their source locations off shelf and under the ice shelf to the continental shelf before being mixed upwards over the course of the last model year. The concentrations of $d y e_{C D W}$ and $d y e_{G M}$ in the surface mixed layer at the end of the first six months is less than $1 \%$, and has no impact on the final values we report. Dye SIM $_{\text {does have }}$ a significant concentration at the end of the first six months, but disperses to extremely low concentrations over the course of the winter, and is likewise negligible.

The fourth dye (dye bdFe $)$ was added as a proxy for benthic iron sources, including sediment efflux and benthic remineralization. Observations from the PRISM-RS cruise of the distribution of dissolved iron near the sea floor were used to set the parameters for $d y e_{b d F e}$. These observations indicate that only locations with bottom depths below 400 meters have enhanced dFe concentrations near the bottom, most likely due to the presence of a benthic nepheloid layer not observed in shallower regions (Marsay et al., 2014). 


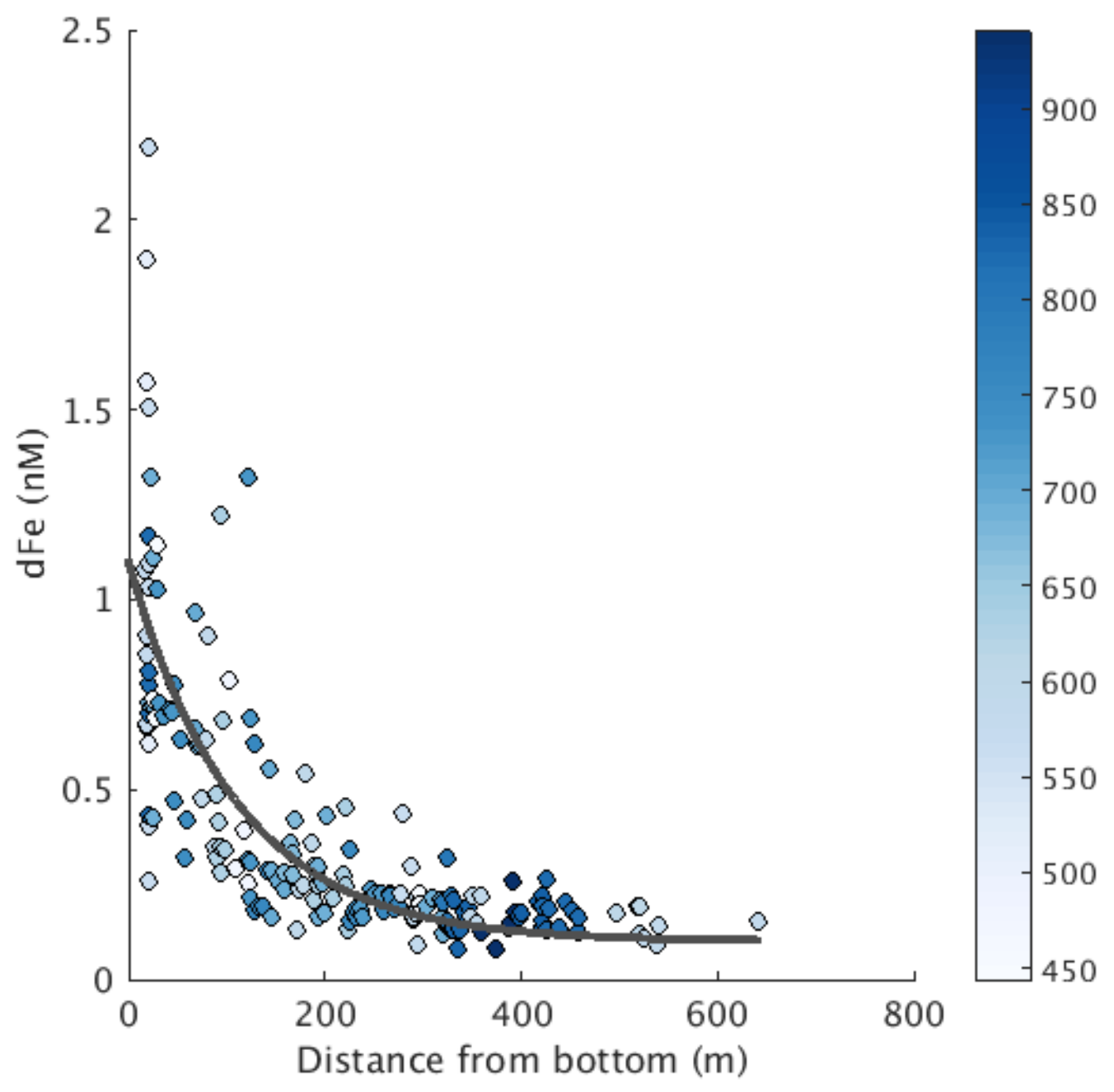

Figure 2: DFe measurements below $200 \mathrm{~m}$ from casts where bottom depth was greater than $400 \mathrm{~m}$, given as a function of distance from the seafloor. Color bar is total water column depth in meters. Black line is exponential fit from equation 1. Adapted from Marsay et al. (2014). 
Following Marsay et al. (2014), all measurements of dFe concentration below 200 meters depth, where the bottom depth was at least 400 meters deep, were fit as a function of height above bottom, $z$, with the suggested exponential:

$$
d F e=0.1 \mathrm{nM}+A e^{B z} .
$$

Applying the fit to all $\mathrm{dFe}$ data (Fig. 2), yields fit parameters $A=0.9973$ and $B=-0.00908$, with $95 \%$ confidence levels of $[0.8837,1.111]$ and [0.01083, -0.007334], respectively. Using this fit, we calculated the estimated concentration of $\mathrm{dFe}$ in the lowest vertical layer in the model at all on-shelf grid points inshore of the $700 \mathrm{~m}$ isobath and deeper than $400 \mathrm{~m}$. The average height above bottom of this layer is $6.57 \mathrm{~m}$ with a range of $4.79 \mathrm{~m}$ to $14.68 \mathrm{~m}$, and the expected dFe concentration at $6.57 \mathrm{~m}$ above the seafloor is $1.04 \mathrm{nM}$ $\pm 0.22 \mathrm{nM}$, which sets the end member for $d y e_{b d F e}$.

In the model, dye $e_{b d F e}$ is initialized at all grid points inshore of the $700 \mathrm{~m}$ isobath, at depths greater than $400 \mathrm{~m}$. Under ice shelf points are excluded, as there is no data to properly represent benthic sources there. The dye is held at a constant value in the bottom layer, allowing transport to be determined by advection, mixing, and turbulent diffusion. It is essentially an infinite source that operates under the assumption that flux into the benthic layer from sediments or remineralization is in steady state with flux out of the benthic layer. As the model represents only physical processes, and not any biological uptake parameters, $d y e_{b d F e}$ is not initialized until the end of the first simulation summer (i.e., March 1, 2011). The dye that makes it to the surface by the end of the simulation represents the input over the course of one year, and thus represents a reasonable estimate of what is available for biological uptake during the growing season. 


\begin{tabular}{c|c|c} 
Dye & dFe End Member $(\mathrm{nM})$ & Source \\
\hline dye $_{C D W}$ & $0.27 \pm 0.05$ & Sedwick et al. (2011); McGillicuddy et al. (2015) \\
dye $_{S I M}$ & $10.0 \pm 5.0$ & McGillicuddy et al. (2015); Lannuzel et al. (2010) \\
dye $_{G M}$ & $29.0 \pm 21.0$ & McGillicuddy et al. (2015) \\
dye $_{b d F e}$ & $1.04 \pm 0.22$ & Marsay et al. (2014)
\end{tabular}

Table 3: End member concentrations for model passive tracer dyes.

This formulation of $d y e_{b d F e}$ allows it to be used not only as a proxy for benthic dFe supply, but also to illustrate vertical mixing on the continental shelf and the lateral advection of benthic waters off shelf.

\subsection{Simulation Significance Criterion}

When comparing simulations, it is useful to have a criterion to determine if solutions are significantly different from one another. As the simulations used here (Table 2) are realistic hindcast simulations for a specific time period, instead of using a traditional ensemble calculation, we develop a Simulation Significance Criterion (SSC), using output from S5, the 20 year simulation with annually repeating forcing, to establish statistical significance.

Perhaps the best way to describe the SSC is with an example. Consider a comparison of $d y e_{G M}$ in the on-shelf SML between the simulations, where $d y e_{G M}$ is a one-dimensional time series. Using STL (Seasonal Trend using Loess (Cleveland et al., 1990)) on $d y e_{G M}$ from simulation S5, we decompose the signal into a non-linear trend, a seasonal cycle, and sub-annual variability (residuals) (Fig. 3). As we are focused on processes on the time scale of one year or less, the sub-annual variability is an appropriate representation of 

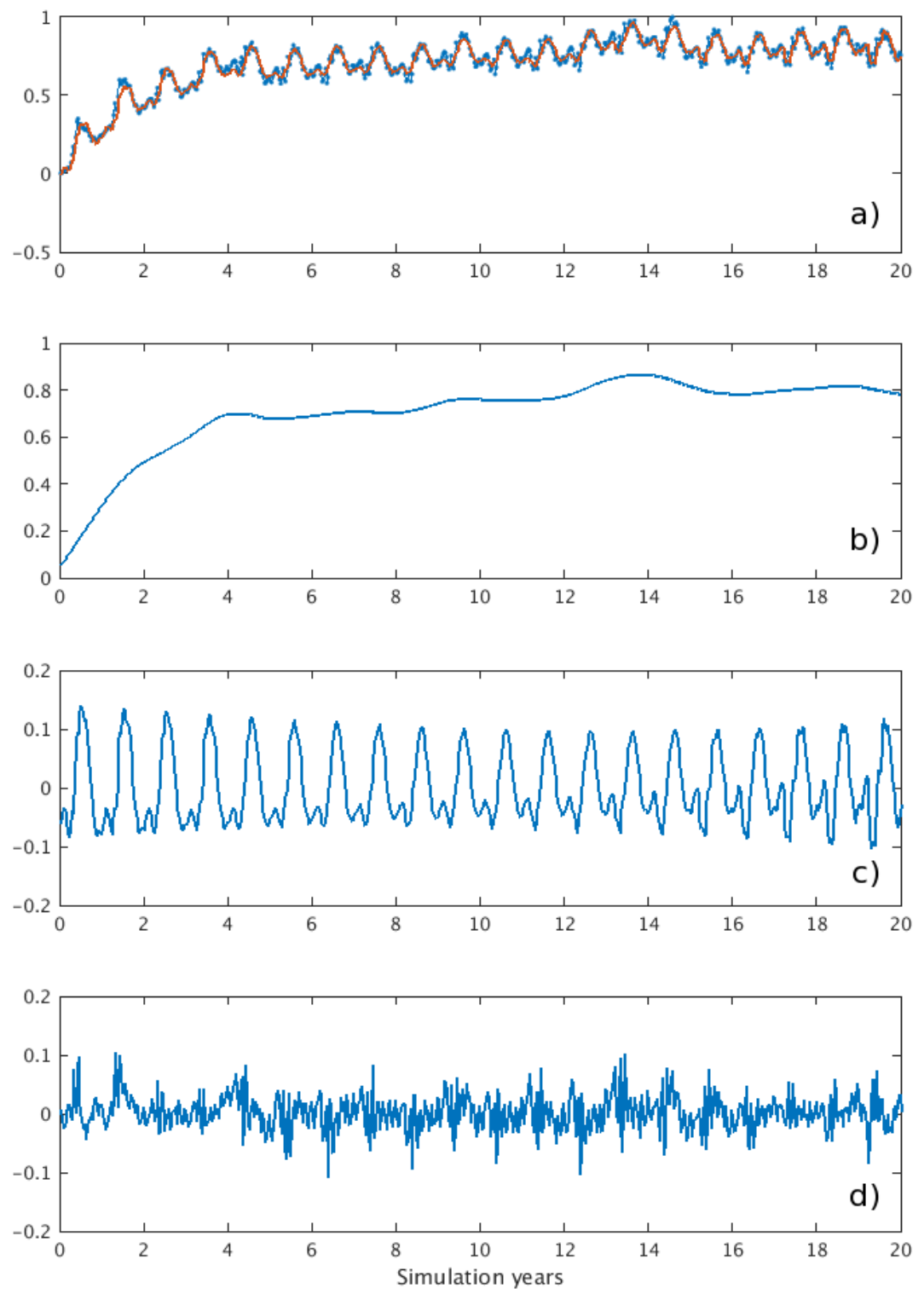

Figure 3: STL (Seasonal Trend using Loess) (Cleveland et al., 1990) decomposition of $d_{y} e_{G M}$ from simulation $\mathbf{S 5}$ with annually repeating forcing. a) Dots are original timeseries normalized by the maximum value, solid line is the fit (trend plus seasonal cycle). b) Nonlinear trend. c) Seasonal cycle. d) Sub-annual variability. 
variability. To quantify this simply, we take the RMS of the sub-annual variability, and divide by the RMS of the rest of the time series (annual fit and non-linear trend), obtaining a fraction (or percent) as a threshold of significance:

$$
S S C=\frac{R M S(\text { subannual })}{R M S(\text { trend }+ \text { fit })} \times 100 \% .
$$

The SSC for $d y e_{G M}$ is $4.11 \%$. If the amount of $d y e_{G M}$ in two different simulations is different by more than the SSC (4.11\%), then we consider the results to be significantly different.

This method can be applied to any variable or parameter expressed as a time series. We apply it specifically to average mixed layer depth and the amount of dye tracers in the SML. Note that even as the model accumulates dye over time (from consistent sources, and export through open boundaries is the only sink), the magnitude of the sub-annual variability (Fig. 3d) stays the same. This is true for all four dyes as well as their sum.

\subsection{Mixed Layer Depth Calculations}

The literature lists many ways to calculate mixed layer depth (MLD), from exceeding a threshold or gradient condition to more involved methods (Holte and Talley, 2009). Here we follow de Boyer Montégut et al. (2004) and apply a threshold method using temperature and density, which has been demonstrated to work well in the Southern Ocean (Dong et al., 2008). For data from the PRISM-RS cruise, we set the reference level to be a depth of $10 \mathrm{~m}$, to avoid ephemeral surface effects. For simulation output, the reference level is set to the top model layer (thickness of $1 \mathrm{~m}$ in shallow areas, and up to $15 \mathrm{~m}$ over abyssal depths). Using the second model layer instead has little to no effect on the end result. 
The MLD is then defined as the shallowest depth below the reference layer that meets the criterion $|\Delta T| \geq 0.2^{\circ} \mathrm{C}$ or $\Delta \rho \geq 0.03 \mathrm{kgm}^{-3}$. For the most part, MLD in the Ross Sea is controlled by salinity gradients, although some locations near the ice shelf front have a shallower mixed layer depth based on the temperature criteria. There are also instances where deep winter mixing reaches the seafloor, and MLD is limited by that depth.

\section{Results}

\subsection{Benthic dye pathways}

Simulation output from simulation $\mathbf{5}$ is used as the base case, and analyzed to determine the pathways of $d y e_{b d F e}$. Starting in March 2011, in the bottom model layer, dye $e_{b d F e}$ is initialized at 100 dye units (which is later converted to nM dFe using Table 3) inshore of the 700 meter isobath only where the water column depth is greater than $400 \mathrm{~m}$ (locations with 100 in the first panel of Fig. 4). DyebdFe is zero elsewhere and at all points under the ice shelf. The dye flows off the western side of the shelf break, approximating the flow of dense High Salinity Shelf Water (HSSW) that sinks and entrains ambient water to form Antarctic Bottom Water(AABW). Dye concentrations here range from 20-30, indicating that the bottom water from the shelf forms $20-30 \%$ of what becomes AABW derived from the Ross Sea. This matches estimates of the benthic layer containing 25\% HSSW off Cape Adare (Gordon et al., 2009), or $30 \%$ at $1500 \mathrm{~m}$ depth on the western continental slope.

In the center of the continental shelf, benthic waters from deeper locations are mixed over the banks during the course of the year. In particular, more than $50 \%$ of the bottom water on Mawson and Ross banks is from deeper 

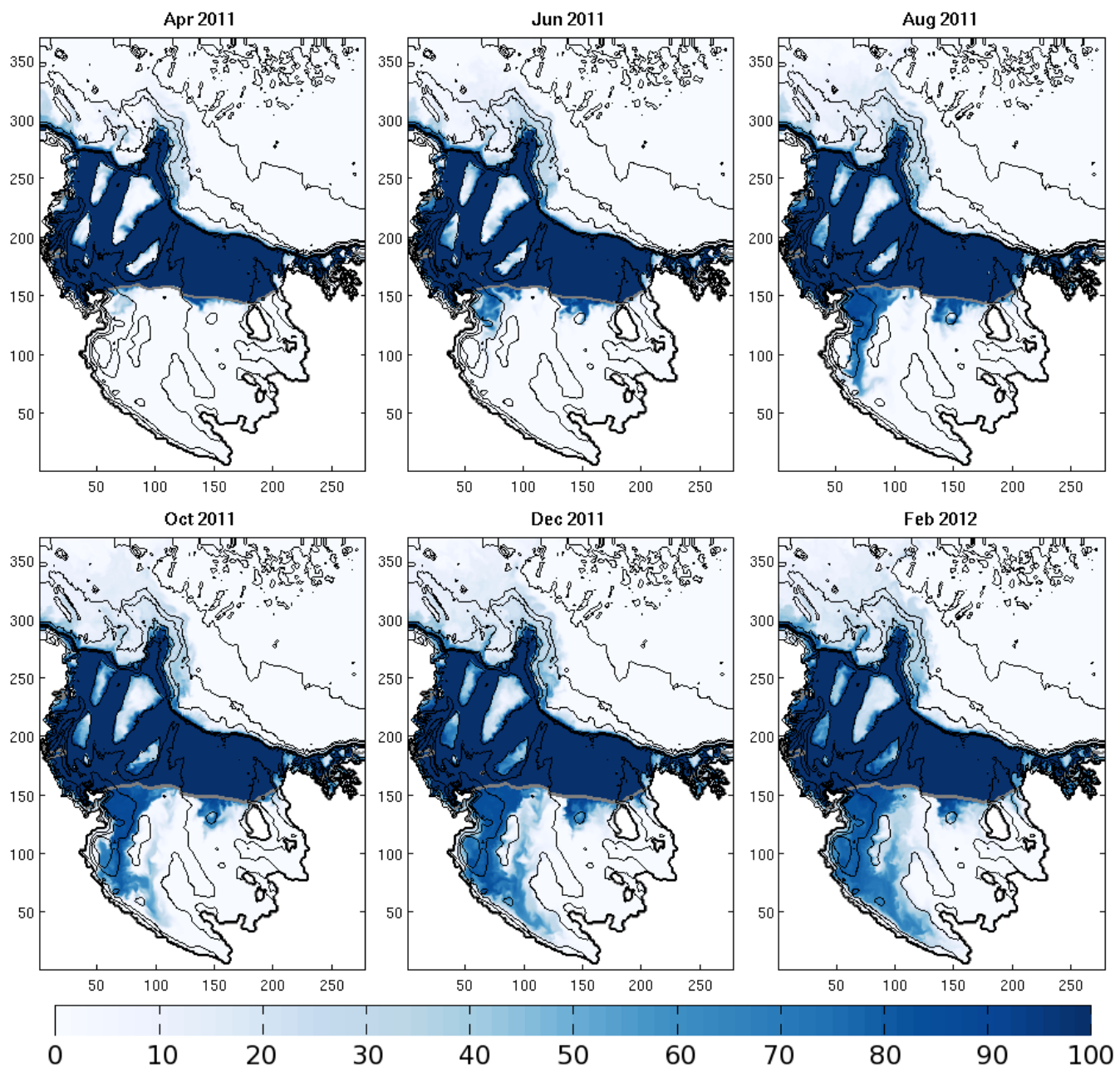

Figure 4: Monthly snapshots of $d y e_{b d F e}$ in the bottom model layer for the last year of simulation 5. Color bar is in dye units, where the dye was initialized at 100. Black lines are bathymetry contours, gray line is the ice shelf front. $\mathrm{X} / \mathrm{Y}$ axes indicate simulation grid points. 
areas of the shelf, while Pennell Bank has significantly less. The depths of these banks are relatively similar, but Pennell is the widest and flattest of the three.

Using a December-January-February (DJF) average, we capture the concentration of the dye during the austral summer months for all simulations (Fig. 5). Increased horizontal resolution in simulations 1 and $\mathbf{1 T}$ shows less dye over Crary bank (south of Mawson), indicating steeper bathymetry at higher resolution redirects benthic flows around the bank, rather than over it. There is also less dye on the far eastern side of the shelf. However, the amount of dye that leaves the shelf in AABW increases.

When tidal forcing is added in simulations $\mathbf{5 T}$ and $\mathbf{1 T}$, the amount of dye over Mawson and Pennell banks increases. A probable mechanism for this increase in $d y e_{b d F e}$ is the increase of onshore velocities with tides along the western side of the banks near the shelf break at depth. Increased energy and mixing sloshes dye from depth up onto the banks from the western side. The same effect is not seen at Ross and Crary banks, as they are too far removed from the shelf break, where tides are weaker.

Surface (i.e., top model layer - several hundred meters below sea level under the ice shelf) $d y e_{b d F e}$ indicates where upwelling and significant vertical mixing occurs (Fig. 6). Two months after the $d y e_{b d F e}$ is initialized, it begins to reach the surface along the front of the Ross Ice Shelf, and near Terra Nova Bay, both persistent polynya locations with strong vertical mixing and sites of HSSW formation. Starting in October, some of the dye leaves the shelf in a surface plume from the eastern side of the shelf break. By the beginning of austral summer, the amount of benthic dye in the surface layer 

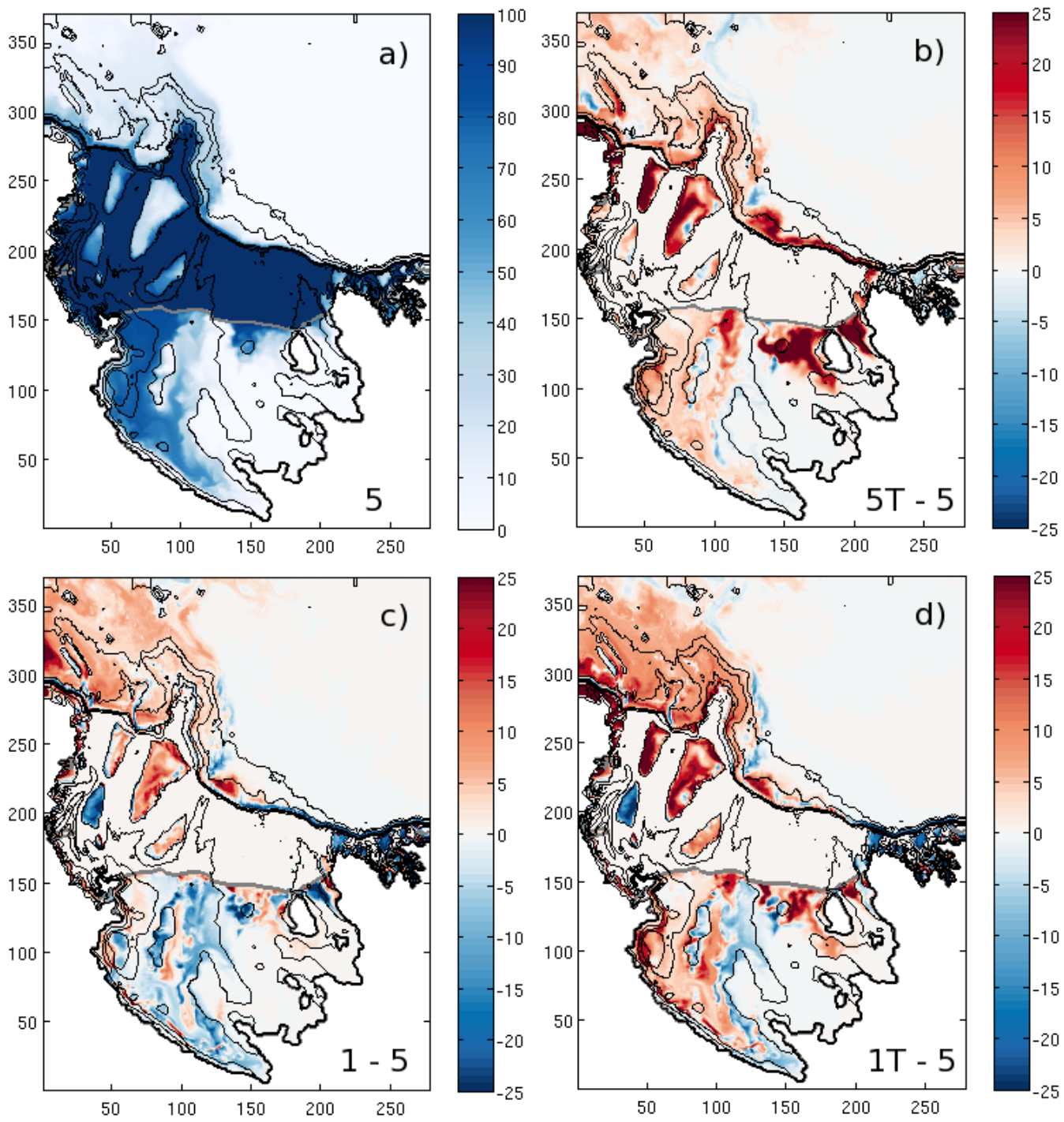

Figure 5: Average amount (DJF) of benthic dye in bottom model layer. a) Results from simulation 5; b,c,d) Difference between simulation 5 and 5T, 1, 1T, respectively. Positive values indicate more dye in that simulation, negative values indicate less. Colorbar is in dye units; black lines are bathymetry; gray line is the ice shelf front. $\mathrm{X} / \mathrm{Y}$ axes indicate simulation grid points from $5 \mathrm{~km}$ grid. 

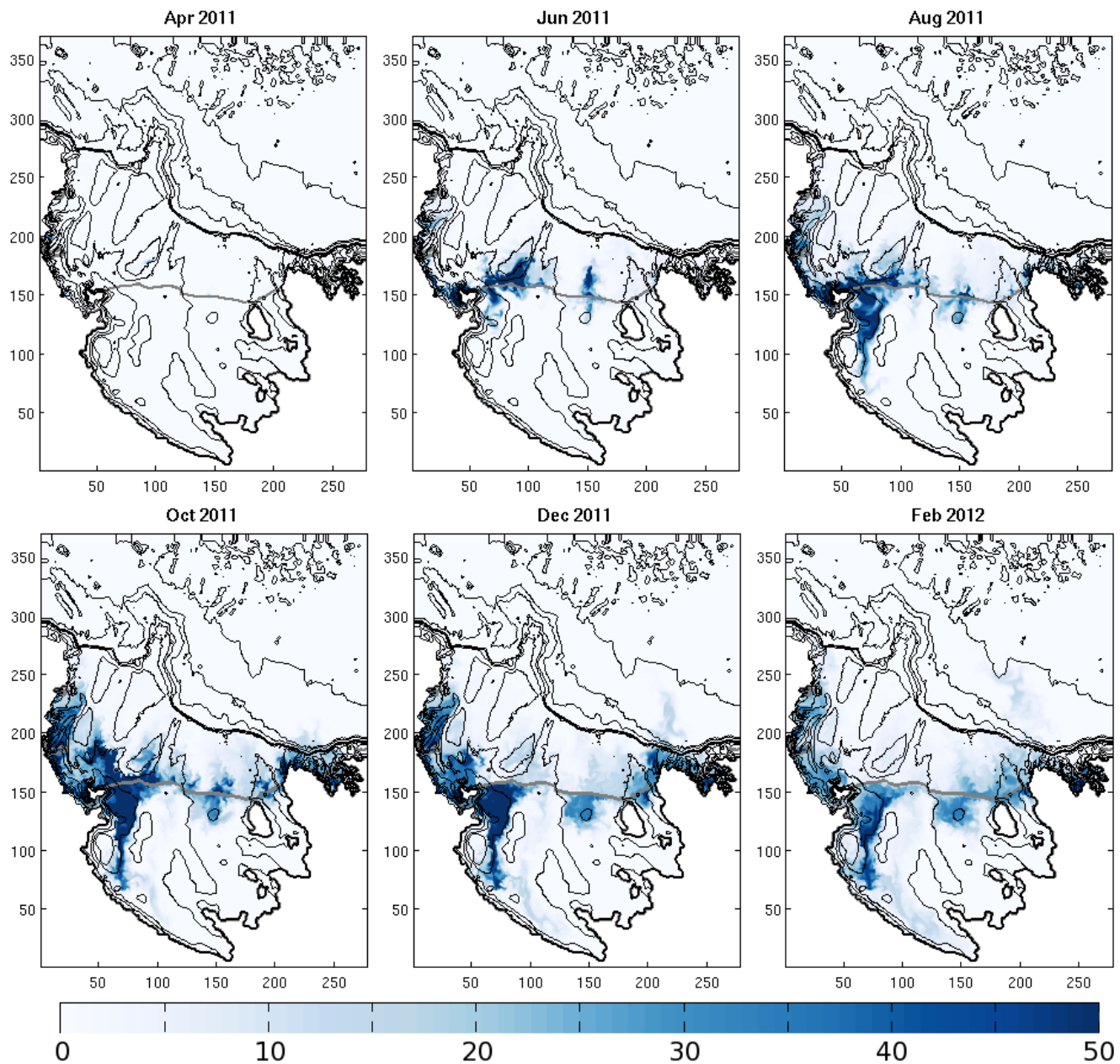

Figure 6: Monthly snapshots of $d y e_{b d F e}$ in the top model layer for the last year of simulation 5. Colorbar is in dye units, where the dye is initialized at 100. Black lines are bathymetry contours, gray line is the ice shelf front. $\mathrm{X} / \mathrm{Y}$ axes indicate simulation grid points. Note the color bar scale is different from Fig. 4 


\begin{tabular}{c|c|c|c} 
Source & J/F MLD & Stdev & SSC \\
\hline $\mathbf{5}$ & $18.32 \mathrm{~m}$ & 7.63 & $\pm 1.085 \mathrm{~m}$ \\
$\mathbf{5 T}$ & $18.71 \mathrm{~m}$ & 7.69 & $\pm 1.108 \mathrm{~m}$ \\
$\mathbf{1}$ & $17.63 \mathrm{~m}$ & 6.31 & $\pm 1.044 \mathrm{~m}$ \\
$\mathbf{1 T}$ & $18.78 \mathrm{~m}$ & 6.50 & $\pm 1.112 \mathrm{~m}$ \\
CTD/VPR & $34.36 \mathrm{~m}$ & 21.31 & $\mathrm{~N} / \mathrm{A}$ \\
Climatology & $20.49 \mathrm{~m}$ & 7.27 & $\mathrm{~N} / \mathrm{A}$
\end{tabular}

Table 4: Average mixed layer depths (MLDs) on the continental shelf for January through February 2012 from simulations, PRISM-RS cruise data, and global climatologies (Kara et al., 2003), given with standard deviations (Stdev). SSC for simulations is shown as the percentage SSC times the average MLD.

on the western side of the shelf has significantly decreased from earlier in the year, indicating that the surface dye has dispersed, and the supply of dye from below has shut down due to less vertical mixing in summer.

DJF average $d y e_{b d F e}$ at the surface (Fig. 7) shows that increased resolution in simulations 1 and $\mathbf{1 T}$ lessens the amount of dye on the eastern side of the shelf. When tidal forcing is added in simulations $\mathbf{5 T}$ and $\mathbf{1 T}$, there is generally more dye over the entire continental shelf, concentrated on the western side, as tides increase vertical mixing. Interestingly, in all simulations except for $\mathbf{5}$, the surface off-shelf plume disappears. One possible explanation for this is that the dye is dispersed vertically due to enhanced vertical mixing from tides at the shelf break, or at higher resolutions, there simply isn't enough dye on the eastern side of the shelf to generate the plume. 

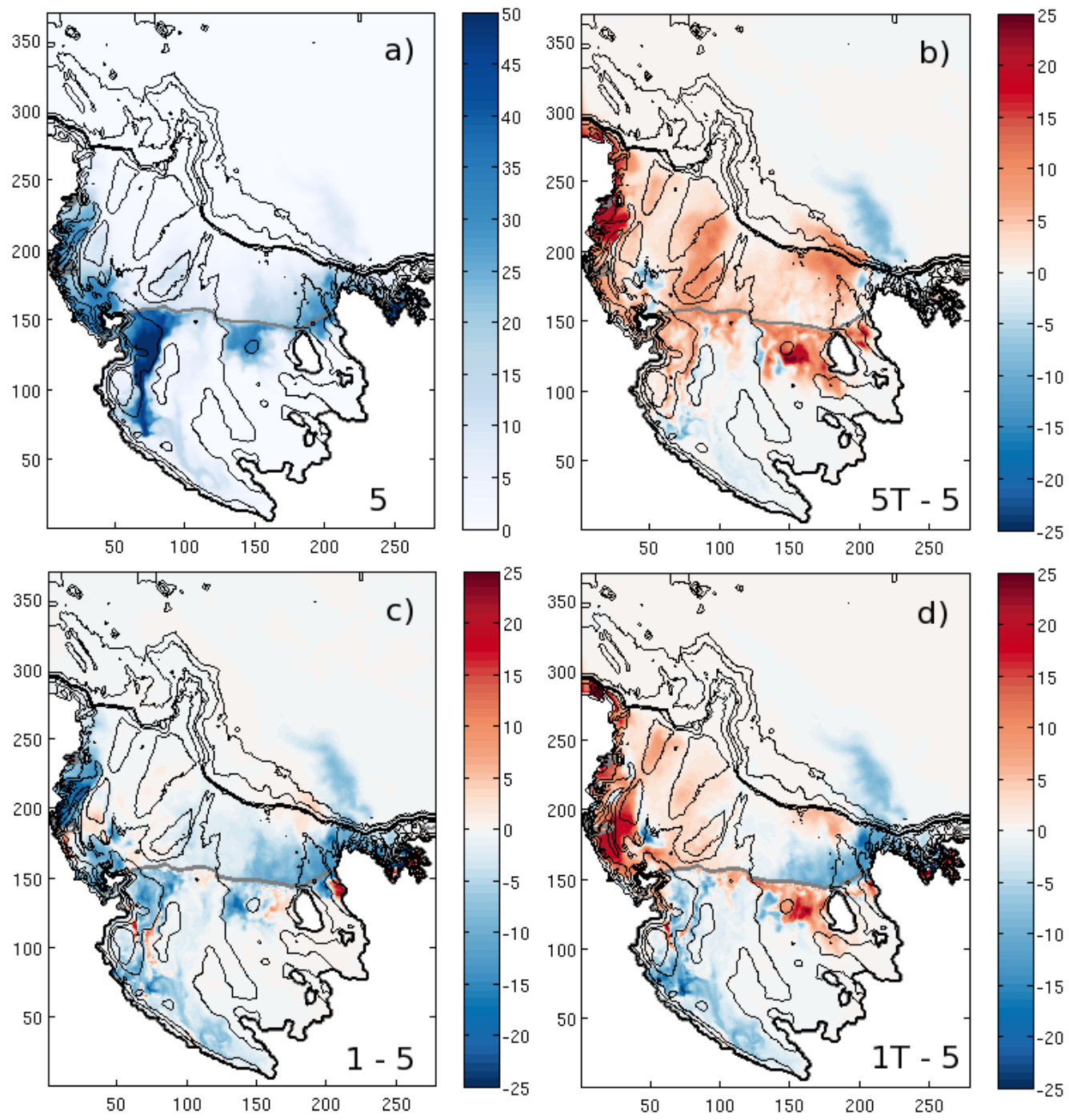

Figure 7: Average amount (DJF) of benthic dye in surface model layer. a) Results from simulation 5; b, c, d) Difference between simulation $\mathbf{5}$ and 5T, 1, 1T, respectively. Positive values indicate more dye in that simulation, negative values indicate less. Colorbar is in dye units; black lines are bathymetry; gray line is the ice shelf front. 

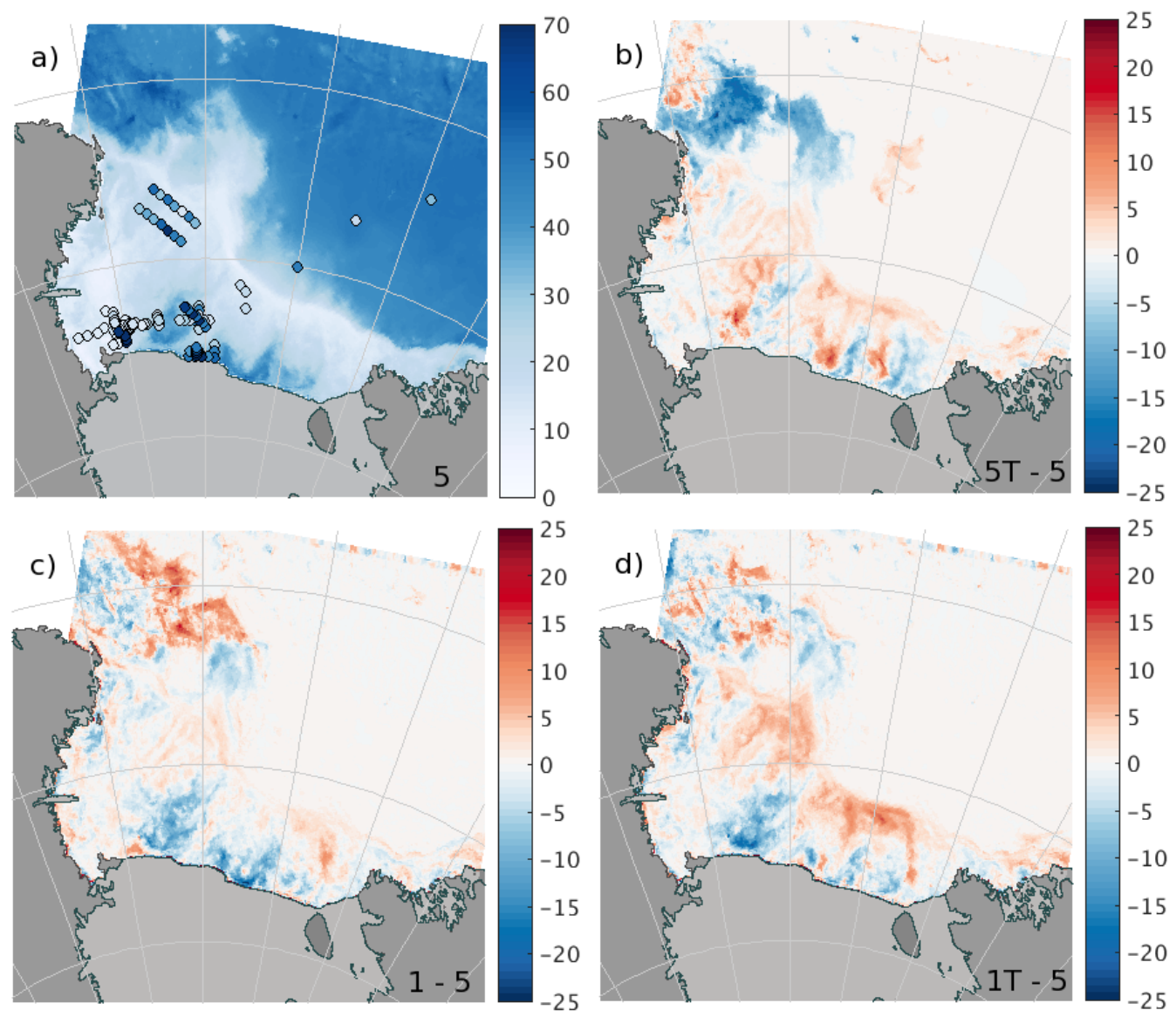

Figure 8: Average mixed layer depth for simulations for January/February. a) Background is simulation 5; dots are MLDs from PRISM-RS CTD stations. b, c, d) Differences between simulation $\mathbf{5}$ and $\mathbf{5 T}, \mathbf{1}, \mathbf{1 T}$, respectively. Positive values indicate increased MLD, negative indicate decreased. 


\subsection{Mixed layer depth}

To calculate how much dFe gets to the surface ocean in the simulations, we define surface ocean as the SML, or the water above the MLD. Using the method described in section 2.5, we determine MLDs for each of the 4 simulations, the PRISM-RS cruise data, and from climatology (Kara et al., 2003) (Table 4). For the simulations and climatology, only MLDs calculated inshore of the simulation defined $700 \mathrm{~m}$ isobath are used, while for PRISM-RS cruise data, all MLDs on the continental shelf from CTD and VPR data are used. Based on the SSC for each simulation the average MLD for JanuaryFebruary 2012 does not significantly vary between simulations. Comparison with climatology gives similar MLD values and similar variability. However, data from the PRISM-RS cruise is quite different, showing a MLD that is significantly deeper, by over $10 \mathrm{~m}$, than climatology or simulation derived values, with much greater variability.

We can refine this analysis by sub-sampling MLDs at CTD stations from the model. Using only MLDs from simulations that are at station locations and within 1 hour of the CTD cast, we find that results stay consistent. Simulations show an average MLD between 17.17 and 18.20 meters, with standard deviations between 8.07 and 10.31, similar to the January-February averages in Table 4. Areas where simulated MLD differs greatly from observed MLDs are along the ice shelf front, and at a few stations over Ross Bank (Fig. 8 and 9). We speculate that the discrepancies in MLD at the ice shelf front are due to biased sampling. Eddies along the ice shelf front were preferentially sampled, and MLDs were much deeper in their cores (Li et al., 2016). In general the model correctly simulates stations that have relatively shallow MLDs, 


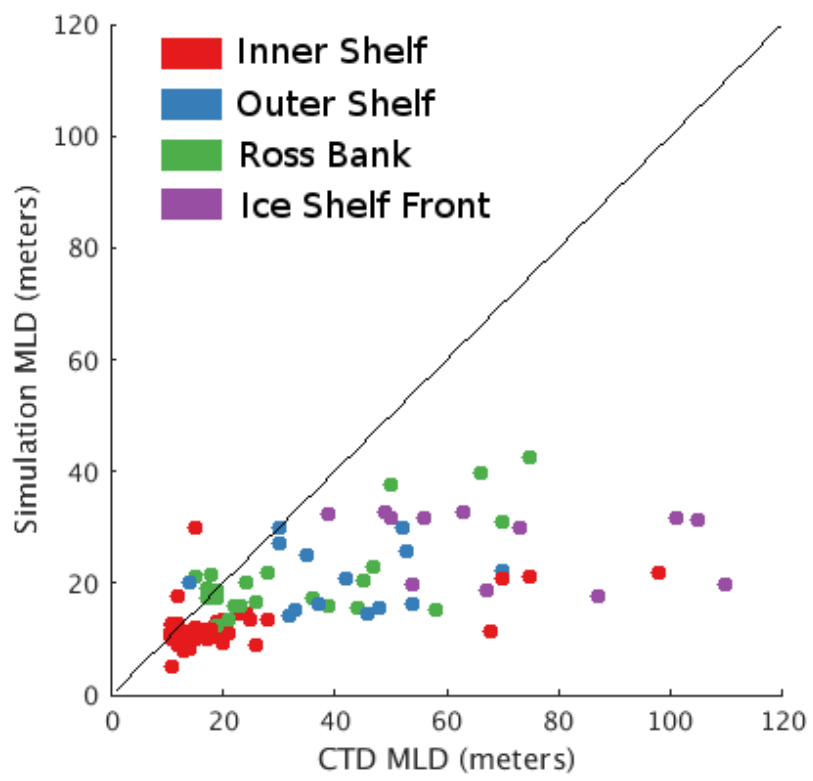

Figure 9: Simulation mixed layer depth (MLD) from simulation 5 at CTD stations and times plotted against CTD observations of MLD. Colors indicate general area of observations. 
but has a more difficult time with deeper MLDs, at least during the summer months. There also is no significant improvement in MLD estimation from simulations $5 \mathrm{~T}, \mathbf{1}$, or $\mathbf{1 T}$.

We argue that this difference in MLDs is a result of the coarseness of resolution of climatological data $\left(1^{\circ}\right)$, and of the atmospheric forcing applied to the model simulations ( $80 \mathrm{~km}$ resolution). A comparison of the PRISM-RS along-track wind speeds with ERA-Interim (Dee et al., 2011) wind speeds used to force the model shows a similar temporal variability, but the maximum observed winds are stronger than those in ERA-Interim. It has previously been shown that increasing the resolution of atmospheric models improves the simulation and strength of coastal winds in the Antarctic (Bromwich et al., 2013; Dinniman et al., 2015) and that this can deepen mixed layers in simulations of the Ross Sea (Mathiot et al., 2012). Thus we suggest that the inability of the simulation to accurately represent MLDs is at least partially the result of the lower resolution of atmospheric data used to force the model.

Comparing the spatial pattern of MLD (Fig. 8), we see that MLDs for the different simulations are by no means the same. When tidal forcing is added to simulation 5, there is a strong decrease in MLD off shelf in the northwest region, primarily because tides help break up the retreating sea ice, allowing shallower MLDs to form earlier (Mack et al., 2013). MLDs on shelf for simulations $\mathbf{5 T}$ and $\mathbf{1 T}$ show a shift in pattern from their non-tidal counterparts: along the ice shelf front some areas become shallower and some deeper. Adding tides at both resolutions also increases the MLD on the outer portion of the shelf, near the shelf break, as tides have the strongest impact 


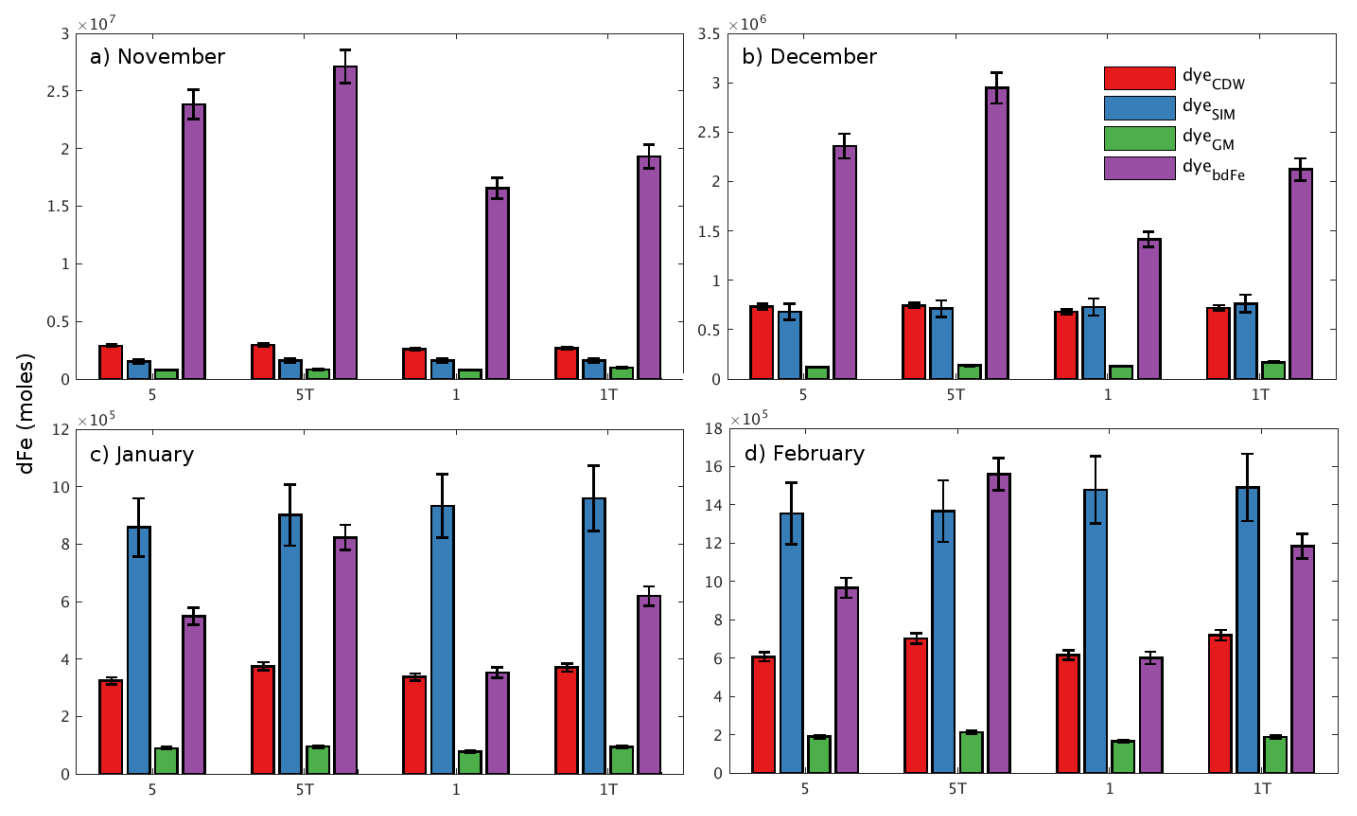

Figure 10: Bar graph showing the contribution of each dFe source to the total amount in the SML on the continental shelf (inshore of $700 \mathrm{~m}$ ). Units are moles dFe. Error bars are SSC. a) November, b) December, c) January, d) February.

there. An increase in horizontal resolution mainly decreases the MLD along the ice shelf front, showing a suppression of vertical mixing, perhaps by eddy activity. There are some complex changes to MLD in off-shelf waters in the northwest as this is an area with fast currents and fairly high eddy activity, modifying MLD at smaller spatial scales.

Overall, while the average MLD does not differ greatly between simulations, the difference in spatial pattern suggests that MLD may play a significant role, alongside actual supply of dFe, in determining how much dFe reaches the SML and is available to support biological production. 


\subsection{Dissolved iron supply}

We first consider the amount of dFe supplied to the SML in each simulation from each source for the final four months of simulation(Fig. 10). These four months cover the time period of the phytoplankton bloom, which can begin as early as mid-November and continues through February (Sedwick et al., 2011). The large changes in y-axis scale in Figure 10 are mainly due to the shallowing of the SML. All four simulations show the same general characteristics as time progresses. The supply of dFe is dominated by dye bdFe in November and December, and decreases as the mixed layer shallows in summer. As sea ice begins to melt, the contribution from dye $e_{S I M}$ increases, roughly matching that of $d y e_{C D W}$ in December, and then dominating in January and February. The amount of $d y e_{b d F e}$ significantly decreases with increased resolution (1 and $\mathbf{1 T}$ ) in all months due to shallower MLDs near the ice shelf front, and decreased vertical mixing on shelf. At the same time, $d y e_{b d F e}$ increases with tides in all months, rendering the net effect of tides and eddies not significant (5 vs $\mathbf{1 T}$ ). Dye $C D W$ shows a similar effect - it increases with the addition of tidal forcing, as tides increase how much CDW intrudes onto the continental shelf (5T and $\mathbf{1 T}$ ), although the magnitude is much less than the changes seen with $d y e_{b d F e}$. Tidal forcing also increases the amount of $d y e_{G M}$ in all months except November, as tidal rectification induces more exchange of waters across the ice shelf front and thus more melting, however the contribution is by far the smallest of the four sources. Dye ${ }_{S I M}$ does not show a significant difference in the amount of dFe supplied between different simulations. Based on this representation of dFe in the SML, January is the first month in which all dye sources are fully developed, and the ice is melted 
enough to allow a significant spring bloom of phytoplankton.

The spatial distribution of $\mathrm{dFe}$ in the mixed layer on the shelf (inshore of $700 \mathrm{~m}$ ) in January illustrates specifically where the total dFe supplied differs between each simulation (Fig. 11). In general, we see higher concentrations of $\mathrm{dFe}$ on the western side of the continental shelf, with the lowest amounts on the middle shelf. When the horizontal resolution is increased (simulations 1 and $\mathbf{1 T}$ ), the concentration of dFe on the eastern side of the shelf decreases while the smaller scale variability along the western side of the shelf shifts. With the addition of tidal forcing (simulations $5 \mathrm{~T}$ and $\mathbf{1 T}$ ), the amount of $\mathrm{dFe}$ increases over almost the entire shelf, and is greatest on the western edge where tides are the strongest.

Iron supply on the shelf in the SML separates into two distinct regions: areas on the outer portion of the shelf or on the western side that are dominated primarily by sea ice melt $\left(d y e_{S I M}\right)$, and areas on the inner shelf that are dominated by benthic iron supply (dye $e_{b d F e}$ ) (Fig. 12). Dye $e_{C D W}$ is the dominant source only over portions of Ross Bank in simulations 5 and $\mathbf{1}$. Glacial melt $\left(d y e_{G M}\right)$ only dominates at locations under the ice shelf where $d y e_{b d F e}$ is not initialized. We define dominance simply as the source that makes up the greatest percentage of $\mathrm{dFe}$ in each grid cell. If we set the threshold for the speckled areas (Fig. 12) to 50\%, the entire model domain, except for some areas along the edge of the ice shelf front, is speckled. Similarly, if we set it to $90 \%$, only a few areas off-shelf dominated by sea ice melt, and deep under the ice shelf on the eastern side, are speckled. This indicates that even though some areas are clearly dominated by one process, there is no location on the continental shelf that is supplied by only one source. Thus, 

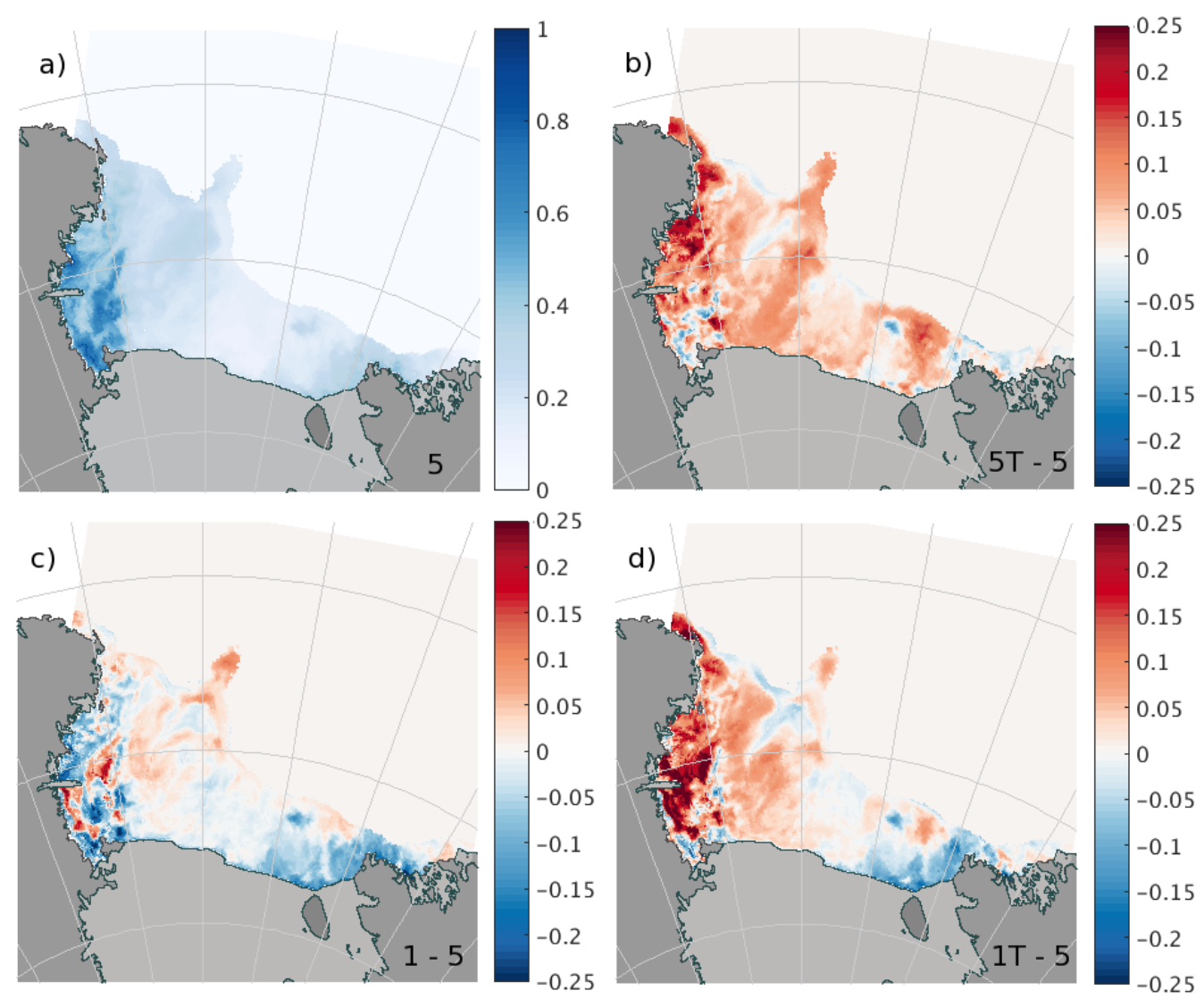

Figure 11: Dissolved iron supply (nM) in the surface mixed layer on the continental shelf (inshore of $700 \mathrm{~m}$ ) for January. a) Simulation 5. b, c, d) Differences between simulation $\mathbf{5}$ and simulations $\mathbf{5 T}, \mathbf{1}, \mathbf{1 T}$, respectively. Positive values indicate more $\mathrm{dFe}$ in the simulation, negative values indicate less. 

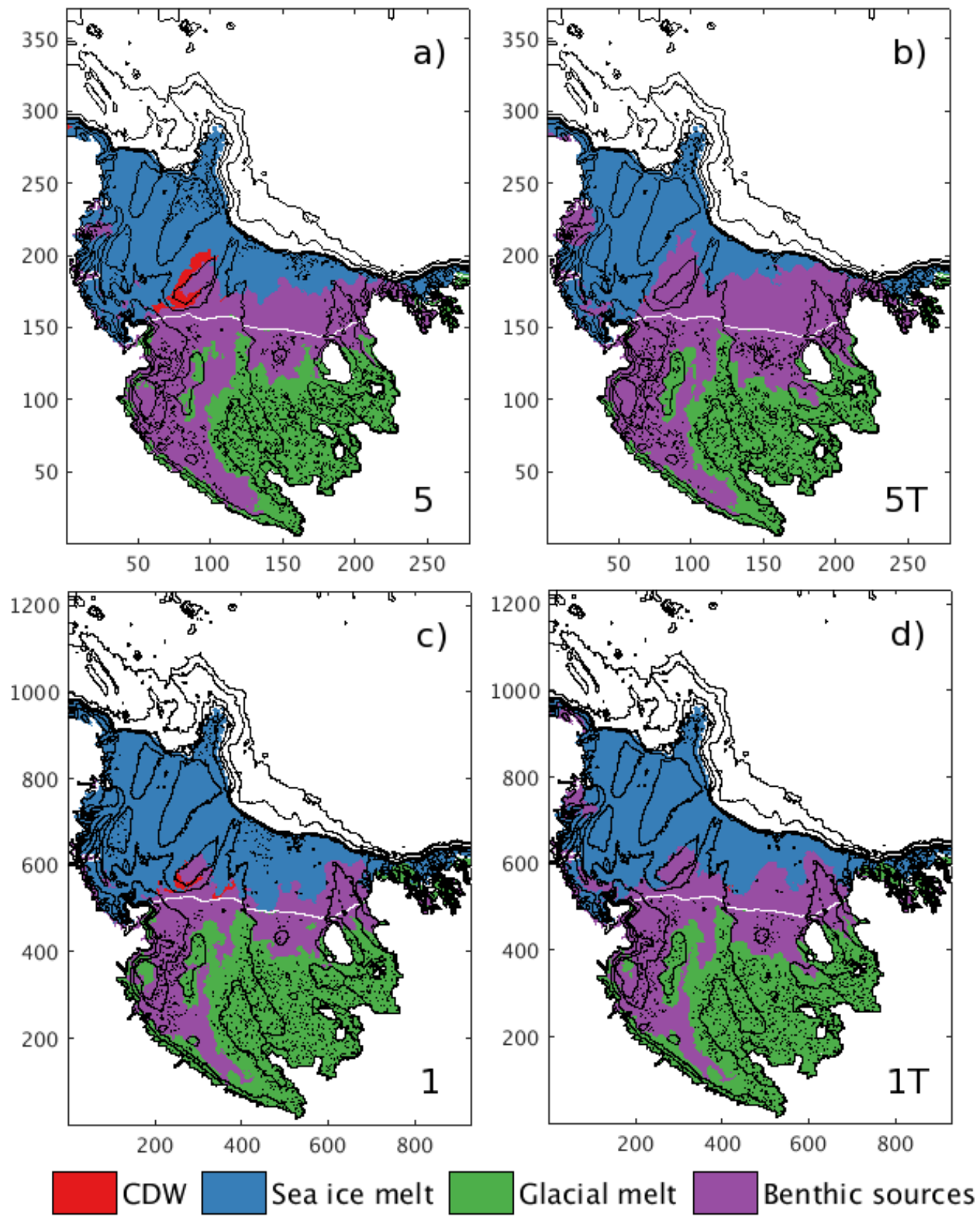

Figure 12: Color indicates dominant source of surface layer dFe for January 2012 for simulations a) $\mathbf{5}$, b) $\mathbf{5 T}$, c) $\mathbf{1}$, d) $\mathbf{1 T}$. Speckled areas indicate that source provides at least $75 \%$ of $\mathrm{dFe}$. Solid black lines are bathymetry; white line is ice shelf front. 


\begin{tabular}{l|c|c|c|c|r} 
Source & $\mathbf{5}$ & $\mathbf{5 T}$ & $\mathbf{1}$ & $\mathbf{1 T}$ & SSC \\
\hline dye $_{C D W}$ & 1.25 & 1.37 & 1.22 & 1.35 & $\pm 3.82 \%$ \\
dye $_{S I M}$ & 2.17 & 2.24 & 2.34 & 2.40 & $\pm 11.80 \%$ \\
dye $_{G M}$ & 0.30 & 0.33 & 0.28 & 0.33 & $\pm 4.11 \%$ \\
dye $_{b d F e}$ & 2.91 & 4.00 & 1.77 & 2.93 & $\pm 5.35 \%$ \\
\hline Total & 6.63 & 7.95 & 5.60 & 7.01 & $\pm 3.83 \%$
\end{tabular}

Table 5: Total dFe in the SML for each simulation from each source on the shelf (inshore of $700 \mathrm{~m}$, averaged over DJF). Units are $\mu \mathrm{mol} \mathrm{m}^{-2} \mathrm{yr}^{-1}$. Final row shows the total $\mathrm{dFe}$ supplied from each simulation.

to understand the supply of dFe on the continental shelf, a comprehensive source analysis is indeed necessary.

\section{Discussion \& Conclusion}

The formulation of $d y e_{b d F e}$ in the model, despite the lack of information regarding direct efflux from sediment and remineralization rates, provides a reasonable representation of how much benthic dFe is supplied to the SML. Results from McGillicuddy et al. (2015) give a total dFe supply of about $7.8 \mu \mathrm{mol} \mathrm{m}{ }^{-2} \mathrm{yr}^{-1}$, while simulation estimates range from 5.60 to $7.95 \mu \mathrm{mol}$ $\mathrm{m}^{-2} \mathrm{yr}^{-1}$. As our formulation for dFe supply from CDW, sea ice melt, and glacial melt is similar to McGillicuddy et al. (2015), this close correspondence indicates that we are using a reasonable representation for benthic $\mathrm{dFe}$ sources. For modeling purposes, an estimate of bottom layer dFe concentration is sufficient, assuming close to steady state. The recent measurements presented by Marsay et al. (2014), and their suggested exponential fit of 
benthic dFe as a function of distance from the sea floor provides a sufficient estimate of benthic dFe concentration on the continental shelf. Similar to Gerringa et al. (2015), we find that the inner shelf region near the Ross Sea polynya is mostly dominated by benthic sources of dFe.

Estimates of iron supply from different simulations in DJF suggest that CDW supplies $17-22 \%$ of dFe to the SML, sea ice melt $28-42 \%$, glacial melt 4$5 \%$, and benthic sources $32-50 \%$ (Table 5). The greatest difference between simulations is in the amount supplied by $d y e_{b d F e}$. Tidal forcing increases the dFe supplied by $d y e_{b d F e}$ by increasing mixed layer depths and increasing vertical turbulent diffusion, while increasing horizontal resolution has the opposite effect. We hypothesize that sharper bathymetry gradients with increased horizontal resolution leads to less upwelling of $d y e_{b d F e}$, and overrides any eddy-induced increase in dFe supply from glacial melt. This trend holds true for the total dFe from all sources, indicating that changes to the benthic dFe supply in simulations dominate the changes to total supply. Interestingly, the net result from adding tidal forcing and increasing horizontal resolution (1T) is not significantly different from the original model configuration (5). Despite a non-significant change in total supply between simulations $\mathbf{5}$ and $\mathbf{1 T}$, we argue that including tidal forcing and high horizontal resolution is necessary to capture the spatial variations in dFe surface concentrations over one year, which vary by up to $\pm 0.25 \mathrm{nM}$. This is particularly true for the banks and the western portion of the continental shelf, which show a significant increase in the amount of $d y e_{b d F e}$ with the addition of tidal forcing.

When considering MLD, and comparing to changes in dFe in different 
simulations, it is interesting to note that areas with the largest changes in MLD (Fig 8) correspond to areas with the least change in total dFe supply between simulations (Fig. 11). Thus the changes to MLD between simulations have a damping effect on the changes in dFe concentration, e.g., a decrease in MLD negates an increase in dFe supply at that location. If we used a constant MLD across simulations, the differences in dFe supply would be amplified. Also of interest is that the locations where the model does poorest in predicting observed MLDs correspond to locations that show the greatest changes in MLDs between simulations, specifically over Ross Bank and along the front of the ice shelf. Again we make the point that atmospheric data of sufficient resolution to resolve short, high intensity storms may make a significant impact on these results.

Important next steps for this work include determining the impact of including tides in high resolution regional models for other Antarctic shelf seas when considering biogeochemical processes in a regional context. Tides are particularly strong in parts of the Ross Sea, while the neighboring Amundsen Sea shows significant effects from resolving mesoscale eddies (St-Laurent et al., 2013). Another important advancement would be to move past the use of dyes alone and couple a biogeochemical model (Tagliabue and Arrigo, 2005 ) to the physical model of the Ross Sea. Parameterizing biological uptake and scavenging would remove $\mathrm{dFe}$ from the model, and simulations run over multiple years would capture inter-annual variability and better constrain the total dFe supply. 


\subsection{Acknowledgments}

The data used in this paper are archived at the Biological and Chemical Oceanography Data Management Office: www.bco-dmo.org/project/2155. The authors acknowledge funding from NSF's Antarctic Research Program (ODU: ANT-0944174; WHOI: ANT-0094165), assistance from S. Howard and S. Spring in adding tidal forcing to the model, and support from members of the PRISM-RS project. Thanks to two anonymous reviewers whose comments greatly improved this manuscript. This research was supported by the Turing High Performance Computing Cluster at Old Dominion University.

\section{References}

Arndt, J.E., Schenke, H.W., Jakobsson, M., Nitsche, F.O., Buys, G., Goleby, B., Rebesco, M., Bohoyo, F., Hong, J., Black, J., Greku, R., Udintsev, G., Barrios, F., Reynoso-Peralta, W., Taisei, M., Wigley, R., 2013. The International Bathymetric Chart of the Southern Ocean (IBCSO) Version 1.0 - A new bathymetric compilation covering circum-Antarctic waters. Geophys. Res. Lett. 40, 3111-3117. doi:10.1002/grl.50413.

Arrigo, K.R., van Dijken, G.L., Bushinsky, S., 2008. Primary production in the Southern Ocean, 1997-2006. J. Geophys. Res. 113. doi:10.1029/2007JC004551.

Årthun, M., Holland, P.R., Nicholls, K.W., Feltham, D.L., 2013. Eddydriven exchange between the open ocean and a sub-ice shelf cavity. J. Phys. Oceanogr. 43, 2372-2387. doi:10.1175/JPO-D-13-0137.1. 
Arzeno, I.B., Beardsley, R.C., Limeburner, R., Owens, B., Padman, L., Springer, S.R., Stewart, C.L., Williams, M.J.M., 2014. Ocean variability contributing to basal melt rate near the ice front of Ross Ice Shelf, Antarctica. J. Geophys. Res. Ocean. 119, 4214-4233. doi:10.1002/2014JC009792.Received.

Boyd, P.W., Arrigo, K.R., Strzepek, R., van Dijken, G.L., 2012. Mapping phytoplankton iron utilization: Insights into Southern Ocean supply mechanisms. J. Geophys. Res. 117. doi:10.1029/2011JC007726.

Bromwich, D.H., Otieno, F.O., Hines, K.M., Manning, K.W., Shilo, E., 2013. Comprehensive evaluation of polar weather research and forecasting model performance in the antarctic. J. Geophys. Res. Atmos. 118, 274-292. doi:10.1029/2012JD018139.

Budgell, W.P., 2005. Numerical simulation of ice-ocean variability in the Barents Sea region. Ocean Dyn. 55, 370-387. doi:10.1007/s10236-0050008-3.

Cleveland, R.B., Cleveland, W.S., McRae, J.E., Terpenning, I., 1990. STL: A seasonal-trend decomposition procedure based on loess. J. Off. Stat. 6, 3-73. doi:citeulike-article-id:1435502.

de Boyer Montégut, C., Madec, G., Fischer, A.S., Lazar, A., Iudicone, D., 2004. Mixed layer depth over the global ocean: An examination of profile data and a profile-based climatology. J. Geophys. Res. 109. doi:10.1029/2004JC002378. 
Dee, D.P., Uppala, S.M., Simmons, A.J., Berrisford, P., Poli, P., Kobayashi, S., Andrae, U., Balmaseda, M.A., Balsamo, G., Bauer, P., Bechtold, P., Beljaars, A.C.M., van de Berg, L., Bidlot, J., Bormann, N., Delsol, C., Dragani, R., Fuentes, M., Geer, A.J., Haimberger, L., Healy, S.B., Hersbach, H., Holm, E.V., Isaksen, L., Kållberg, P., Köhler, M., Matricardi, M., McNally, A.P., Monge-Sanz, B.M., Morcrette, J.J., Park, B.K., Peubey, C., de Rosnay, P., Tavolato, C., Thépaut, J.N., Vitart, F., 2011. The ERAInterim reanalysis: configuration and performance of the data assimilation system. Q. J. R. Meteorol. Soc. 137, 553-597. doi:10.1002/qj.828.

Dinniman, M.S., Klinck, J.M., Bai, L.S., Bromwich, D.H., Hines, K.M., Holland, D.M., 2015. The Effect of Atmospheric Forcing Resolution on Delivery of Ocean Heat to the Antarctic Floating Ice Shelves. J. Clim. 28, 6067-6085. doi:10.1175/JCLI-D-14-00374.1.

Dinniman, M.S., Klinck, J.M., Smith, W.O., 2007. Influence of sea ice cover and icebergs on circulation and water mass formation in a numerical circulation model of the Ross Sea, Antarctica. J. Geophys. Res. 112. doi:10.1029/2006JC004036.

Dinniman, M.S., Klinck, J.M., Smith, W.O., 2011. A model study of Circumpolar Deep Water on the West Antarctic Peninsula and Ross Sea continental shelves. Deep Sea Res. Part II 58, 1508-1523. doi:10.1016/j.dsr2.2010.11.013.

Dong, S., Sprintall, J., Gille, S.T., Talley, L., $2008 . \quad$ Southern Ocean mixed-layer depth from Argo float profiles. J. Geophys. Res. 113. doi:10.1029/2006JC004051. 
Durski, S.M., 2004. Vertical mixing schemes in the coastal ocean: Comparison of the level 2.5 Mellor-Yamada scheme with an enhanced version of the K profile parameterization. J. Geophys. Res. 109, C01015. doi:10.1029/2002JC001702.

Falkowski, P.G., Ziemann, D., Kolber, Z., Bienfang, P.K., 1991. Role of eddy pumping in enhancing primary production in the ocean. Nature 352, $55-58$.

Flather, R., 1976. A tidal model of the northwest European continental shelf. Mem. Soc. R. Sci. Liege 10, $141-164$.

Fretwell, P., Pritchard, H.D., Vaughan, D.G., Bamber, J.L., Barrand, N.E., Bell, R., Bianchi, C., Bingham, R.G., Blankenship, D.D., Casassa, G., Catania, G., Callens, D., Conway, H., Cook, A.J., Corr, H.F.J., Damaske, D., Damm, V., Ferraccioli, F., Forsberg, R., Fujita, S., Gim, Y., Gogineni, P., Griggs, J.A., Hindmarsh, R.C.A., Holmlund, P., Holt, J.W., Jacobel, R.W., Jenkins, A., Jokat, W., Jordan, T., King, E.C., Kohler, J., Krabill, W., Riger-Kusk, M., Langley, K.A., Leitchenkov, G., Leuschen, C., Luyendyk, B.P., Matsuoka, K., Mouginot, J., Nitsche, F.O., Nogi, Y., Nost, O.A., Popov, S.V., Rignot, E., Rippin, D.M., Rivera, A., Roberts, J., Ross, N., Siegert, M.J., Smith, A.M., Steinhage, D., Studinger, M., Sun, B., Tinto, B.K., Welch, B.C., Wilson, D., Young, D.A., Xiangbin, C., Zirizzotti, A., 2013. Bedmap2: improved ice bed, surface and thickness datasets for Antarctica. Cryosph. 7, 375-393. doi:10.5194/tc-7-375-2013.

Gerringa, L., Laan, P., van Dijken, G., van Haren, H., De Baar, H., Arrigo, 
K., Alderkamp, A.C., 2015. Sources of iron in the ross sea polynya in early summer. Mar. Chem. 177, 447-459.

Gordon, A.L., Orsi, A.H., Muench, R., Huber, B.A., Zambianchi, E., Visbeck, M., 2009. Western Ross Sea continental slope gravity currents. Deep Sea Res. Part II 56, 796-817. doi:10.1016/j.dsr2.2008.10.037.

Haidvogel, D.B., Arango, H., Budgell, W.P., Cornuelle, B.D., Curchitser, E., Di Lorenzo, E., Fennel, K., Geyer, W.R., Hermann, A.J., Lanerolle, L., Levin, J., McWilliams, J.C., Miller, A.J., Moore, A.M., Powell, T.M., Shchepetkin, A.F., Sherwood, C.R., Signell, R.P., Warner, J.C., Wilkin, J., 2008. Ocean forecasting in terrain-following coordinates: Formulation and skill assessment of the Regional Ocean Modeling System. J. Comput. Phys. 227, 3595-3624. doi:10.1016/j.jcp.2007.06.016.

Hallberg, R., 2013. Using a resolution function to regulate parameterizations of oceanic mesoscale eddy effects. Ocean Model. 72, 92-103. doi:10.1016/j.ocemod.2013.08.007.

Holte, J., Talley, L., 2009. A New Algorithm for Finding Mixed Layer Depths with Applications to Argo Data and Subantarctic Mode Water Formation*. J. Atmos. Ocean. Technol. 26, 1920-1939. doi:10.1175/2009JTECHO543.1.

Kara, A.B., Rochford, P.A., Hurlburt, H.E., 2003. Mixed layer depth variability over the global ocean. J. Geophys. Res. 108. doi:10.1029/2000C000736.

Lannuzel, D., Schoemann, V., de Jong, J., Pasquer, B., van der Merwe, P., Masson, F., Tison, J., Bowie, A., 2010. Distribution of dissolved iron 
in Antarctic sea ice: Spatial, seasonal, and interannual variability. J. Geophys. Res. 115, G03022. doi:10.1029/2009JG001031.

Large, W.G., McWilliams, J.C., Doney, S.C., 1994. Oceanic vertical mixing: A review and a model with a nonlocal boundary layer parameterization. Rev. Geophys. 32, 363-403.

Li, Y., McGillicuddy Jr., D.J., Dinniman, M.S., Klinck, J.M., 2016. Processes regulating formation of low-salinity high-biomass lenses near the edge of the Ross Ice Shelf. J. Mar. Syst. this issue.

MacAyeal, D.R., 1985. Tidal rectification below the Ross Ice Shelf, Antarctica. Antarct. Res. Ser. 43, 109-132.

Mack, S., Padman, L., Klinck, J., 2013. Extracting tidal variability of sea ice concentration from amsr-e passive microwave single-swath data: a case study of the ross sea. Geophysical Research Letters 40, 547-552.

Makinson, K., Holland, P.R., Jenkins, A., Nicholls, K.W., Holland, D.M., 2011. Influence of tides on melting and freezing beneath Filchner-Ronne Ice Shelf, Antarctica. Geophys. Res. Lett. 38. doi:10.1029/2010GL046462.

Marsay, C.M., Sedwick, P.N., Dinniman, M.S., Barrett, P.M., Mack, S.L., McGillicuddy Jr., D.J., 2014. Estimating the benthic efflux of dissolved iron on the Ross Sea continental shelf. Geophys. Res. Lett. 41, 7576-7583. doi:10.1002/2014GL061684.Received.

Mathiot, P., Jourdain, N.C., Barnier, B., Gallee, H., Molines, J.M., Sommer, J.L., Penduff, T., 2012. Sensitivity of coastal polynyas and high-salinity 
shelf water production in the Ross Sea, Antarctica, to the atmospheric forcing. Ocean Dyn. 62, 701-723.

McGillicuddy, D., Sedwick, P.N., Dinniman, M.S., Arrigo, K.R., Bibby, T.S., Greenan, B.J.W., Hofmann, E., Klinck, J.M., Smith Jr., W.O., Mack, S.L., Marsay, C.M., Sohst, B.M., van Dijken, G.L., 2015. Iron supply and demand in an Antarctic shelf ecosystem. Geophys. Res. Lett. 42. doi:10.1002/2015GL065727.

McGillicuddy Jr., D.J., 2016. Mechanisms of Physical-BiologicalBiogeochemical Interaction at the Oceanic Mesoscale. Ann. Rev. Mar. Sci. 8, 13.1-13.36. doi:10.1146/annurev-marine-010814-015606.

Mueller, R.D., Padman, L., Dinniman, M.S., Erofeeva, S.Y., Fricker, H.A., King, M.A., 2012. Impact of tide-topography interactions on basal melting of Larsen C Ice Shelf, Antarctica. J. Geophys. Res. 117, C05005. doi:10.1029/2011JC007263.

Padman, L., Erofeeva, S., Joughin, I., 2003. Tides of the Ross Sea and Ross Ice Shelf cavity. Antarct. Sci. 15. doi:10.1017/S0954102002.

Padman, L., Howard, S.L., Orsi, A.H., Muench, R.D., 2009. Tides of the northwestern Ross Sea and their impact on dense outflows of Antarctic Bottom Water. Deep Sea Res. Part II 56, 818-834. doi:10.1016/j.dsr2.2008.10.026.

Robertson, R., 2013. Tidally induced increases in melting of Amundsen Sea ice shelves. J. Geophys. Res. Ocean. doi:10.1002/jgrc.20236. 
Sedwick, P.N., Marsay, C.M., Sohst, B.M., Aguilar-Islas, A.M., Lohan, M.C., Long, M.C., Arrigo, K.R., Dunbar, R.B., Saito, M.A., Smith, W.O., DiTullio, G.R., 2011. Early season depletion of dissolved iron in the Ross Sea polynya: Implications for iron dynamics on the Antarctic continental shelf. J. Geophys. Res. 116. doi:10.1029/2010JC006553.

Shchepetkin, A.F., McWilliams, J.C., 2005. The regional oceanic modeling system (ROMS): a split-explicit, free-surface, topographyfollowing-coordinate oceanic model. Ocean Model. 9, 347-404. doi:10.1016/j.ocemod.2004.08.002.

Shchepetkin, A.F., McWilliams, J.C., 2009. Correction and commentary for Ocean forecasting in terrain-following coordinates: Formulation and skill assessment of the regional ocean modeling system by Haidvogel et al., J. Comp. Phys. 227, pp. 35953624. J. Comput. Phys. 228, 8985-9000. doi:10.1016/j.jcp.2009.09.002.

Smith, W.O., Ainley, D.G., Cattaneo-Vietti, R., 2007. Trophic interactions within the Ross Sea continental shelf ecosystem. Philos. Trans. R. Soc. B 362, 95-111. doi:10.1098/rstb.2006.1956.

Song, Y., Haidvogel, D., 1994. A semi-implicit ocean circulation model using a generalized topography-following coordinate system. J. Comput. Phys. $115,228-244$.

St-Laurent, P., Klinck, J.M., Dinniman, M.S., 2013. On the Role of Coastal Troughs in the Circulation of Warm Circumpolar Deep Water on Antarctic Shelves. J. Phys. Oceanogr. 43, 51-64. doi:10.1175/JPO-D-11-0237.1. 
672 Tagliabue, A., Arrigo, K.R., 2005. Iron in the ross sea: 1. impact on co2 673 fluxes via variation in phytoplankton functional group and non-redfield 674 stoichiometry. J. Geophys. Res. Oceans 110.

675 Wang, Q., Danilov, S., Hellmer, H., Sidorenko, D., Schröter, J., Jung, T., 676 2013. Enhanced cross-shelf exchange by tides in the western Ross Sea. 677 Geophys. Res. Lett. 40, 5735-5739. doi:10.1002/2013GL058207. 